\title{
EL PAPEL DE LAS REDES FAMILIARES EN LA CONFIGURACION DE LA ELITE DE PODER CENTROAMERICANA (El caso de la familia Díaz Durán).
}

\author{
Marta Elena Casaús Arzú*
}

I. Marco teórico: Las redes familiares como estructuras de larga duración.

71 estudio de las familias, como unidad metodológica y de análisis para la comprensión de la estructura social latinoamericana, representa un nuevo enfoque de las ciencias sociales y aparece vinculado a las temáticas propias de la historia social.1

La importancia que cobran las redes familiares a lo largo de la historia en América Latina y, sobre todo, su vigencia en el presente para la comprensión e interpretación de la estructura social y de poder de las sociedades americanas, se produce allí donde existe una presencia de población indígena, donde el factor socio-racial ocupa un lugar preeminente a la hora de estudiar la configuración de la estructura social colonial y donde se ha producido un escaso proceso de modernización de las estructuras políticas y sociales, en sociedades eminentemente agroexportadoras, en las que el patrón patriarcal continúa ocupando un lugar relevante en el conjunto de la sociedad.

* Pofesora titular de Historia de América. Universidad Autónoma de Madrid.

Coordinadora del Area de Centroamérica de CEDEAL. 
La familia como red o costelación familiar, y sobre todo como estructura de larga duración, continúa desempeñando un rol decisivo en el análisis del conjunto de la estructura social y sobre todo como élite de poder.

Definimos red familiar: el conjunto de familias que configuran la élite de poder y que conforman en cada país el núcleo oligárquico. Estas redes están ligadas por cinco factores que les confieren una unidad y homogeneidad que les permiten constituirse como estructura de larga duración. A saber:

1. Las alianzas a través del matrimonio.

2. Las alianzas mediante los negocios.

3. La proximidad geográfica y el factor socio-racial.

4. La participación en asociaciones políticas, religiosas o socio-culturales.

5. La formación de sus propios intelectuales orgánicos que aseguran a su red la correlación de fuerzas en el bloque de poder que les permite ejercer el dominio.

Estas redes familiares empiezan a configurarse en las sociedades coloniales en torno a los primeros conquistadores y pobladores que comienzan a apoderarse de las principales fuentes de riqueza: la encomienda, el repartimiento, la mita,la tierra.

El principal factor de excedente económico de estas familias va a estar vinculado al trabajo forzoso a través de la mita y la encomienda y posteriormente a la tierra a través del repartimiento y la composición.2

El. principal factor de acumulación de poder político va a estar determinado por el control de los cargo locales, principalmente el Cabildo, las Alcaldías menores y los Corregimientos, comprando posteriormente otros cargos propios del gobierno peninsular. ${ }^{3}$

Mediante la combinación de los factores anteriormente mencionados, pero sobre todo a través de los casamientos y estrategias matrimoniales y de la reproducción de estos matrimonios, se irá configurando una amplia tela de araña que se fortalecerá mediante relaciones de consanguinidad, extendiéndose verticalmente y a través de lazos sanguíneos y relaciones agnaticias, como mecanismos de acaparamiento de poder político y económico. 
La familia actuará como entidad colectiva básica de la sociedad colonial y como principal institución de acumulación y concentración de poder y a su vez como principal mecanismo de reproducción ideológica del racismo y de los valores propios de la sociedad colonial. La endogamia de las redes familiares y los mecanismos de movilidad ascendente vinculados principalmente al factor socio-racial, al status y a la riqueza van a ser los elementos determinates para la configuración del vértice de la pirámide social colonial.4

Así pues, estudiamos la familia como empresa básica, como grupo relacional, como entidad colectiva y como estructura de poder, a través de las relaciones interpersonales que ésta establece entre su mismo grupo y con el resto de la sociedad civil, con los que suele establecer relaciones de dominio y de subordinación.

A nuestro juicio, la base de esta estructura social está compuesta por familias primarias y secundarias, entendiendo por aquéllas las familias principales, que Balmori denomina "notables", que por su acumulación primaria de capital económica, por su estrategia de establecer exitosas alianzas matrimoniales y de negocios, por el manejo patrimonial de la redes y el establecimiento de redes regionales de largo alcance y por la capacidad de sus intelectuales orgánicos de lograr la pervivencia de su estirpe, han podido vertebrar la estructura social y política durante tres o más generaciones, logrando que su estirpe haya sobrevivido a los avatares de la historia - Conquista, Independencia, período liberal, etc. - siendo las continuidades más comunes que las rupturas. 5

Por familias secundarias entendemos aquellas que van formar constelaciones o que emparentan con las familias primarias, para conseguir formar parte del bloque de poder, reforzando con ello el dominio y legitimación de la red principal.

En cada siglo o período histórico surgirán una o dos familias principales en torno a las cuales van a girar las familias secundarias constituyendo un tupido entramado de relaciones interpersonales, cuyos intereses como clase y como élite de poder serán coincidentes; el elemento aglutinador a nivel ideológico y político va a recaer sobre sus intelectuales orgánicos, cuya función principal será la de asegurar a su red familiar la hegemonía social y el control político, 
legitimando así su dominación en el bloque de poder. 6

Otro hecho relevante, que les ha permitido sobrevivir en períodos de crisis económica y de vacío de poder, ha sido su capacidad de diversificar su economía y de ocupar el lugar del Estado para preservar su dominio y mantenerse en el bloque de poder. En cada etapa histórica han sobrevivido las familias que diversifican su produccón en época de crisis económica y que introducen nuevos productos, mejoran sus técnicas productivas o amplían su capital hacia nuevos mercados.7

Según Balmori, Voss y Wortman, estas redes familiares van a funcionar como una corporación y se les puede considerar como una organización comercial, como una asociación de poder y dinero a lo largo de tres generaciones. Para estos autores, la primera generación realizó una actividad económica, generalmente el comercio y después diversificó su producción. La segunda generación ocupó cargos públicos y creó instituciones políticas que sirvieron a sus intereses, valiéndose además de los cargos públicos, en los cabildos, como gobernadores, diputados, para acumular mayor poder económico. La tercera generación se lanzó a la conquista del Estado, estableciendo alianzas regionales de negocios y matrimoniales hasta llegar a copar el Estado Nación. Para los autores, el cénit de estas redes familiares fue el final del siglo XIX, cuando las redes familiares aparecen ocupando la burocracia, extendiendo su influencia a los principales cargos de la administración pública, en pocas palabras, poseyendo el control de Estado.

"Durante tres generaciones, a través de redes familiares que se iban adaptando a las cambiantes circunstancias, habian extendido continuamente su dominio y su autoridad más allá de los distritos y de las localidades coloniales de los Borbones. Al cabo de más de un siglo, ellos eran los centros de poder y autoridad en todos los niveles de sus sociedades nacionales. 8

Nosotros no compartimos totalmente este planteamiento por considerarlo muy funcional y porque adolece de una cierta ahistoricidad, en la medida en que, de acuerdo con el planteamiento estructural-funcionalista, las instituciones sociales tendrían inevitablemente que pasar por un proceso de nacimiento, crecimiento desarrollo, decadencia y muerte, esta premisa aplicada a las redes 
les lleva a confirmar la tesis generacional, a pesar de que el trabajo de campo no compruebe esta hipótesis. A nuestro juicio, en el caso de las redes familiares centroamericanas, lo que puede apreciarse a través de un estudio histórico-estructural es precisamente su "larga duración" y su capacidad de mimetismo y metamorfosis a lo largo de la historia.

Precisamente lo que nosotros demostramos en nuestro trabajo de investigación sobre las redes familiares en Guatemala, en el libro Guatemala: Linaje y racismo, 9 es su capacidad de supervivencia, gracias a que cambian y se transforman a lo largo de la historia pero no desaparecen, sino que se recrean y modifican, través de los mecanismos mencionados anteriormente: alianzas matrimoniales, relaciones endogámicas y estrategias de sus intelectuales orgánicos, con el fin de mantenerse en el bloque dominante configurándose una auténtica élite de poder y en muchas ocasiones confundiéndose con ella. Así, en diversos períodos de la historia latinoamericana, red familiar y élite de poder son sinónimos y operan como un todo y de forma dialéctica.10

¿Por qué se consolidan estas relaciones de parentesco como auténticos núcleos de poder y dominación en ciertas sociedades latinoamericanas como Centroamérica, Ecuador, Perú, y por qué se constituyen en estructuras de larga duración en donde la continuidad es la norma y no la ruptura, ni tampoco el análisis generacional?

A nuestro juicio la explicación hay que buscarla en varias direcciones que deben formar parte de las líneas prioritarias de investigación en futuros análisis de redes y relaciones interpersonales. Avanzamos algunas premisas que consideramos básicas para la profundización teorico-metodológica en estos temas:

En primer lugar, porque tradicionalmente en España, la familia $y$ las relaciones interpersonales jugaban un rol determinante en la configuración de estructuras de poder, Ida Altman en su estudio sobre Emigración y sociedad, Extremadura y América en el siglo XVI, estudia la familia como la institución legal y económica más importante en Extremadura, la que distribuía la propiedad y los ingresos del conjunto de la red. Similares estudios se han hecho de la sociedad vasca con resultados parecidos. El hogar familiar, opi- 
na Ida Altman,

" sobrepasaba los limites de la familia nuclear para incluir a otros parientes, legitimos e ilegitimos y a personas sin lazos de parentesco... Las familias, los hogares y las parentelas se constituian en jerarquias bajo la autoridad del patriarca" 11.

Este patrón familiar se traslada a América y los lazos de parentesco se fortalecen debido a la lejanía y a la necesidad de proteger y hacer preservar su estirpe, tratando de consolidar su linaje a ambos lados del Océano.

En segundo lugar, porque la presencia de otros grupos socioraciales, indios y negros, obliga a los españoles de la segunda y tercera generación, a casarse entre ellos con el fin de preservar su pureza de sangre y asegurar su hegemonía social y política sobre el resto de la población pluriétnica, distanciándose de ese modo, de los mestizos, indios, negros y otras castas. De esta manera se configura una pirámide rígida, vertical y endogámica que muchos autores han denominado sociedad de castas. El factor socio-racial opera como un mecanismo fundamental de legitimación ideológica y política sobre el resto de los colonizados y como un factor de cohesión social entre ellos, en donde la familia y las alianzas matrimoniales juegan un papel determinante en la reproducción de su estirpe.

En este marco, las relaciones de género van a jugar un papel fundamental en la reproduccióil, preservación e internalización de los valores dominantes. Las mujeres ejercen una gran influencia en la reproducción, preservación e internalización de los valores dominantes. Las mujeres gozarán de una gran influencia en la reproducción del patrón familiar de tipo patriarcal y contribuirán notablemente a la expansión de su red familiar. 12

La dicotomía existente entre criollos y peninsulares en esta sociedad de castas y que tanto ha dado que hablar, por su contraposición con una una sociedad de clases con intereses contrapuestos, no es más que un estigma o un prejuicio socio-racial a la hora de medir el pulso del grupo que más control económico o político ejercia en la sociedad colonial. De hecho, y en la práctica, fueron más comunes las relaciones matrimoniales y de negocios entre estos dos grupo socio-raciales que las pugnas intergrupales, como 
podemos observar en los trabajos de investigación empírica: Peire, Langue, De la Tabla Ducasse, Casaús.13

En tercer lugar, la importancia de las redes familiares como estructuras de poder político de larga duración y como auténticas fuentes de poder de la sociedad colonial. Este poder viene conferido por el hecho de ser las fuentes de poder y legitimación más fuertes, estables y continuadas de la sociedad civil, las únicas que seguían perviviendo a lo largo de los siglos, en la medida en que las autoridades metropolitanas eran transitorias y contradictorias en sus intereses frente a la sociedad colonial y a la Corona. Posiblemente en ello radique una de las diferencias básicas entre las élites de poder europeas, basadas más en relaciones de clientelismo que en relaciones de parentesco.14

Su periodo de gobierno oscilaba entre 5 a 10 años, para luego volverse a la metrópoli o decidir pactar con las redes familiares locales, si querían mantenerse como grupo dominante en el poder. De ahí sus contradicciones y su ambigüedad en cuanto a la élite de poder local, a quien despreciaban y a la vez envidiaban, pero de la que no podían prescindir si querían asegurarse su futuro.

El otro factor determinante era la lejanía del poder metropolitano y la dificultad de hacer cumplir la ley y de ejercer el dominio a tantas leguas de distancia y con las dificultades y peculiaridades que cada sociedad tenía a la hora de aplicar las reales Cédulas y el corpus legal de la Corona. Por ello las relaciones clientelares más provechosas para los actores sociales no pasaban únicamente por estrechar relaciones interpersonales con las autoridades metropolitanas, sino por asegurarse el control de la sociedad a través de las alianzas con los criollos. Así pues, la continuidad de las estructuras sociales y políticas pasaba indefectiblemente por las alianzas entre las redes familiares locales de criollos y los peninsulares. 15

En cuarto lugar, porque ante una crisis económica y un vacío de poder, propios de la situación colonial y sobre todo a partir de la Independencia, son las redes familiares las que copan la sociedad política y ejercen su dominio desde el Estado. No olvidemos que la enorme fortaleza de las redes familiares radica en que surgen y controlan amplios espacios de la sociedad civil y solo en época de crisis o debilidad del Estado ocupan la sociedad política, 
teniendo la capacidad de retornar al ámbito civil, cuando se reestructura el equilibrio del bloque histórico y cuando logran recomponer su correlación de fuerzas en el bloque de poder. En esa capacidad de amalgamar sociedad civil y política, de jugar dialécticamente en ambas esferas, combinando su poder económico con el poder político en época de crisis, es donde radica su fortaleza y su invulnerabilidad y es lo que les convierte en auténticas élites de poder y en estructuras de larga duración.16

A nuestro juicio esta capacidad de mimetismo y permeabilidad social obedecen a una estrategia de las redes de crear, en cada coyuntura histórica, pactos interelitarios para mantenerse en el bloque de poder y en ocasiones - cuando la coyuntura les es propicia- establecen pactos con la sociedad civil, con las otras clases subalternas, con el fin de consolidar su dominio y de asegurar su hegemonía durante largos períodos. La estrategia "pactista" o contractual de las redes familiares parece otra constante en el modus operandi de esta élite de poder y una de las vías más utilizadas para legitimar su hegemonía. Tal vez este tipo de pactos se hagan más evidentes a partir de la constitución del Estado Oligárquico, pero habría que estudiarlo con mayor detenimiento durante el período colonial.17

En quinto lugar, uno de los mecanismos que mayor fortaleza confiere a las redes familiares y que hace que se constituyan en élites permanentes, son los mecanismos de ejercicio del poder. En la combinación de tipos de dominio y diferentes formas de legitimación, dependiendo del período histórico y de la coyuntura política, radica una de sus mejores estrategias de dominación. Tradicionalmente estas redes familiares ejercen un tipo de dominio tradicional-carismático respecto de los grupos subalternos, que se traduce en un tipo de relaciones "patron-cliente" y un tipo de subordinación basado en la lealtad, la confianza y el compadrazgo de camarillas o constelaciones familiares, que, en cada siglo, generalmente van a girar en torno a una o dos redes familiares que ejercen su dominio de forma patrimonial, patriarcal y endogámica.

Estas relaciones de subordinación serán la única forma de dominación durante todo el período colonial. Con la Independencia y la génesis del Estado liberal, el tipo de dominio se ejerce a través 
de la figura del caudillo y las formas de legitimación están vinculadas al carisma del líder, iniciándose nuevas formas de legitimación de carácter legal-racional con la configuración del Estado oligárquico.18

No obstante esta legitimidad, basada en un nuevo orden jurídico liberal y legitimada por la norma y el pacto social entre ciudadanos, no es más que la expresión de un reducido número de familias de " notables" que configurarán un tipo de Estado Nación de corte liberal, logrando de este modo institucionalizar su tipo de dominación tradicional, mediante normas jurídicas de carácter racional. 19

La creencia de que este tipo de legitimidad era válido para el conjunto de la sociedad civil ha sido un espejismo, ya que solo representaba los intereses de un nucleo oligárquico ilustrado, generalmente compuesto por redes familiares tradicionales que lograron crear un Estado a imagen y semejanza de sus intereses, convirtiendo la legitimidad tradicional en legalidad racional válida para el conjunto de la sociedad. Este pacto de dominación es el que se ha reproducido desde entonces hasta nuestros días, con la ausencia o escasa presencia de otros actores sociales. 20

En sexto lugar, uno de los elementos básicos que aseguran su permanencia en el bloque de poder y la pervivencia de su linaje como estructuras de larga duración, es la creación de sus propios intelectuales orgánicos, en cada periodo histórico, quienes, como opina Gramsci, cumplen con una cuádruple función: organizan la estructura económica y son portavoces de la ideología de su grupo, hacen corresponder la concepción del mundo de la clase dominante con el conjunto de la sociedad y sobre todo establecen alianzas y crean mecanismos para establecer la legitimación y el consenso de la sociedad en su conjunto. En otras palabras ejercen la dirección ideológica y política de su grupo y representan casi siempre los intereses de su red familiar.21

A nuestro juicio estas redes familiares basadas en estructuras de parentesco de larga duración, van a constituir una de las principales fuentes de poder colonial y siguen constituyendo, en sociedades agro-exportadoras y con dificultades de consolidación del Estado y resabios de sociedades de casta, importantes fuentes de 
poder, con la presencia de fuertes grupos de interés, que ejercen el dominio mediante el empleo de la fuerza, en ciertas ocasiones, y en otras, logran la hegemonía a través del establecimiento de nuevas alianzas con sectores emergentes de la sociedad.

Este último fenómeno es el que podemos observar a partir de las elecciones de 1990, pero remontando su proceso de reestructuración y recomposición a la década anterior y, no obstante, para su origen, preeminencia y capacidad de metamorfosis hay que buscarlo en el germen de la sociedad colonial.

A continuación nos detendremos en el análisis prosopográfico de una de las familias, Los Díaz Durán, por considerar que representa el modelo de red familiar oligárquica por excelencia, que mediante el establecimiento de inteligentes estrategias matrimoniales y de negocios va generando una amplia élite familiar de larga duración, que en períodos de crisis de dominación, contará con el apoyo de sus intelectuales orgánicos, quienes van a hacer posible la continuidad de su estirpe y a permitir que su red siga formando parte de la élite de poder.

La familia Diaz Durán, que sobrevivió a los avatares de la historia, especialmente durante los cambios profundos del siglo XIX, y no perdió su capacidad de influencia política desde el período colonial, puede ser catalogada como una élite modernizante a lo largo de la historia, debido a que desde el siglo XVII, que se asienta en El Salvador hasta el siglo XX, que se consolida en Guatemala, ha sabido liderar los cambios económicos, tecnológicos y políticos y adecuarse a las nuevas corrientes ideológicas y culturales del momento. En períodos de crisis del sistema, ha sido capaz de amoldarse a las transformaciones políticas de su tiempo, a pesar de que en algún momento, ello resultara contrapuesto al imaginario politico de su clase.

A pesar de no ser una red excesivamente extensa ni una de las más poderosas de la oligarquía guatemalteca, siempre ha contado en su seno con importantes hombres de negocios, políticos, diplomáticos y académicos, que han sido protagonistas históricos de relevancia en periodos de crisis o transición.

Indudablemente el prototipo de red familiar y élite de poder por excelencia a lo largo de tres siglos en Guatemala ha sido la 
familia Aycinena, como lo fueron los Sola Meza Ayau, Dueñas para El Salvador, los Prado para Sao Paulo, los Nuñez del Castillo, Zaldivar, Echevaria para Cuba, o los Cervantes o Tapia Carvajal en México.22 Pero nos interesan los Díaz Durán, Arzú, Chamorro, Lacayo, Skinner Klee, Murray Meza, en Centroamérica, por su proyección en el siglo $X X$, por la capacidad de sus intelectuales orgánicos para que su red subsista en el bloque de poder y por el rol que estoś personajes han jugado en los procesos de recomposición y reciclaje de sus familias en la última década.

Qué duda cabe, en el caso de Guatemala, que Fernando Andrade Díaz Durán desempeñó un papel determinante en el proceso de apertura política en Guatemala en 1984, como Cristiani Burkhart y Murray Meza, han protagonizado el proceso de negociación desde la cúpula, o como Lacayo-Chamorro han liderado la transición en Nicaragua. En pocas palabras, miembros de las redes familiares oligárquicas que se han convertido en auténticas élites dirigentes y gobernantes retornando al poder por la via de las urnas..$^{23}$

Nos parece interesante realizar un análisis diacrónico y sincrónico de esa red familiar, sus ramificaciones regionales y sus alianzas locales para entender la mecánica de funcionamiento de las redes familiares como élites de poder.

De las veintidós familias guatemaltecas estudiadas, hemos seleccionada a la familia Díaz Durán, por el poder que ha ido adquiriendo en los últimos años, producto de sus estrategias familiares, en los negocios, en la política y en la ampliación de su red familiar, y específicamente por considerar que, es una red que desde el inicio forma parte de la élite de poder y que por sus características económicas, políticas y culturales posee un perfil modernizante .

A lo largo de su historia generacional, desde sứ llegada a El Salvador, a finales del siglo XVII, muchos de sus miembros han jugado un papel relevante en la política, la economía, la cultura o las artes. Su descendencia se remonta a personajes históricos claves para la Historia de Centroamérica, como el conquistador Sancho de Barahona, los presidentes de la Audiencia, Alonso Lopez Cerrato y Antonio Lara Mogrovejo, A partir del siglo XVIII presentan un patrón modernizante, impulsando los procesos de cambio y renovación, incorporando normas seculares y una cierta racionalización 
del trabajo y de la política, aceptando ciertas reformas sociales y políticas, aún a costa de chocar con el pensamiento tradicional de su grupo social. Importan modelos de vida y patrones culturales europeos que suponian una clara innovación en sociedades provincianas y endogámicas como las centroamericanas.

Otro de los motivos de interés para nosotros es la pervivencia de esta red como élite de poder y élite dirigente a lo largo de toda la historia centroamericana, logrando sobrevivir a las crisis e incluso participando activamente en algunas coyunturas históricas para encontrar alternativas regionales a la crisis de poder. Algunos de sus miembros, Joaquín Díaz Durán, Jose María Díaz Durán, Manuel José Durán, Fernando Andrade Díaz Durán, jugaron importantes roles en períodos de transición política y supieron articular los intereses de su clase con el imaginario de la Modernidad, haciendo posible de este modo su supervivencia en el bloque de poder. Un papel semejante jugaron otros miembros de las élites familiares, como Antonio Batres Jaúregui, Jose Cecilio del Valle o Manuel José Arce en el siglo XIX, cuya su capacidad política e intelectual y las alianzas familiares que logran conjugar en torno suyo consiguieron recomponer el bloque hegemónico desplazando unas élites de poder por otras o llegando a un pacto entre ellas, con el fin de conservar el dominio y en algunas ocasiones lograr la hegemonía de su clase.

Un estudio prosopográfico de estas redes y una parametrización de estas élites y su irrupción en la Modernidad nos parece de vital importancia en la historia política centroamericana para poder comprender a la élite de poder en la actualidad.24

\section{La participación política de la familia Díaz Durán y de otras redes familiares en la Modernidad.}

\section{Antecedentes históricos:}

Ta familia Durán procede de Extremadura, Don Bernardo fue LCapitán y Contador de las Reales Cajas en Perú y posteriormente se trasladó a San Salvador, donde fijó su residencia. Su hijo Bernardo Durán y Baca, fue Alcalde ordinario de San Salvador. Casó con Antonia Nuñez de Guzmán, una de las familias fundadoras y descendientes de conquistadores, que se asienta en El Sal- 
vador y que posee una amplia fortuna desde sus inicios. (Véase Diagrama de los Díaz Durán -Núñez de Guzmán- Aguilar). Ambas familias poseían importantes propiedades agrícolas en El Salvador, eran dueños de una hacienda de 40 caballerias que producían ganado y añil.25 ( Véase Diagrama 2)

Su hija Juana Durán y Núñez de Guzmán, casó con Manuel Herrera. Desconocemos si esta familia Herrera tiene relación con la de Guatemala. Ana Herrera y Durán casó con Domingo Durán y Hernández que fue Regidor del Ayuntamiento de El Salvador. Otro de sus hijos Jose Durán y Nuñez de Guzmán casó con Ana Hernández y Escalante, otra de las familias más ricas de El Salvador. Un hijo de este matrimonio, Juan Francisco Durán y Hernández, casa con Mónica de Aguilar y Nava en 1783.

Con estos tres matrimonios claves dentro de las estrategias matrimoniales del peninsular, Bernardo Durán y Baca, en menos de un siglo había logrado emparentar con las redes familiares locales más acaudaladas y más influyentes de El Salvador: Núñez de Guzmán, Aguilar, Escalante, Ladrón de Guevara, Arce, Bustamente, etc. La consolidación de su red estaba asegurada, era preciso lanzarse a la conquista del poder político local y ampliar la red a nivel regional.

Fue en el siglo XVII, cuando los Durán pasaron a Guatemala, posiblemente debido a las actividades políticas de algunos de sus miembros y a la estrategia familiar de cubrir el espacio regional. Sin duda alguna el miembro de la familia que jugó un papel decisivo en este período fue Joaquín Díaz Durán y Aguilar. Este fue Ministro de El Salvador durante el gobierno de la Federación Centroamericana. Posteriormente fue nombrado por el gobierno de Guatemala para desempeñar altos cargos: Secretario de la Gobernación de Estado en 1839, Secretario de Gobernación, Guerra y Negocios Eclesiásticos, Diputado por el Distrito de Antigua, Delegado conjuntamente con Rafael Carrera para ajustar el tratado de paz con el gobierno de El Salvador, Secretario de Relaciones Exteriores en 1844 y Presidente de Guatemala por unos meses, en 1845. Por su labor conciliadora y por el conocimiento de la región se pudo firmar con el gobierno de Honduras el tratado de paz.

Su hija, Ana Josefa Durán casa con un primo hermano Jose María Díaz Durán y es esta linea troncal Díaz Durán y Durán, la 
que va a producir mayor número de políticos, diplomáticos e intelectuales orgánicos en El Salvador, Honduras y en Guatemala.

Dos hermanos de Joaquín, jugarán papeles claves en la consolidación y extensión de la red al resto de la región centroamericana: Manuel José Durán y Aguilar, ocupó varios cargos públicos en El Salvador y Guatemala, fue Administrador General de Rentas en 1845, casa con Cornelia Inchaurregui y posteriormente emparentará con la familia Valladares, Santis y Gálvez. María Antonia Durán y Aguilar, contrajo matrimonio en la Antigua, con Joaquín María Diaz del Castillo y Cárcamo, descendiente directo de Bernal Díaz del Castillo y una de las élites de poder más permanentes de la historia de Guatemala.

María Antonia Durán y Aguilar jugará un papel clave en la ampliación de la red familiar de los Díaz Durán en Guatemala y en la elaboración de una compleja estrategia familiar para sus hijas y nietas. A su vez, por su carácter y personalidad fue una de las primeras mujeres empresarias de la Antigua Guatemala, abriendo un comercio en esta ciudad.

Uno de sus hijos, Jose María Díaz Durán, se convirtió en un gran terrateniente en la Antigua, poseyendo importantes fincas de café:" el Zapote" donde poseía 88 caballerías para la cría de ganado, café y caña de azúcar. Casa con su prima hermana, Josefa Durán en 1842. De este matrimonio nacerán tres hijos, que empezarán a emparentar con las redes familiares más tradicionales de Guatemala sin perder sus vínculos con la región centroamericana a través de la familia Valle de origen hondureño y de las familias Aguilar Escalante y Arce de origen salvadoreño.

Otro de los enlaces exitosos de esta rama fue el matrimonio de María Antonia Díaz Durán y Durán con Francisco Camacho y Gallegos. Tres de las hijas de este matrimonio: Concepción, Ana y María Camacho Díaz Durán, emparentan con dos diplomáticos peninsulares de gran renombre, Castro y Casaleiz y Villaurrutia, ambos con título nobiliario, y la tercera emparenta con una de las mayores fortunas del país, también de origen extranjero, Carlos Novella Klee. Esta nueva generación entronca con el capital extranjero a finales del siglo XIX, permitiéndole a esta familia ampliar su red y vincularse a una nueva fase de expansión y de inserción con el 
Es esta misma rama de los Díaz Durán la que emparentará más tarde con los Andrade Mazariegos, a través del matrimonio de María con Flavio, cuyos hijos más prominentes, en el ámbito politico-diplomático y económico serán Rodolfo y Fernando Andrade Diaz Durán, que seguirán la tradición de su familia, como veremos posteriormente.

Los diagramas que a continuación presentamos muestran solo algunas de las redes matrimoniales que establecen los Díaz Durán, una vez que se asientan en Guatemala a partir del siglo XDX. En ellos se encuentran las principales familias que conforman el bloque hegemónico en la actualidad. Entre ellos podemos observar sus vínculos con los Klee, Shwank, Herrera, Castillo Lara, Castillo Love, Paiz, Falla, Cofiño, Ariz, Alejos, Aguirre, Saravia, Novella, Arrivillaga. ( diagrama 3 y 4)

Los Díaz Durán logran unificar en las redes familiares las familias de mayor tradición y abolengo, Camacho, Cofiño, Saravia, Arzú, Alvarez de las Asturias, Urruela, Aguilar, Beltranena, Arce, Valle, con aquellas que hicieron sus fortunas a partir de 1871, como los Herrera y Samayoa, con el capital alemán, a través de los Kepfer, Klee, Spatz, Swank y con capital italiano e inglés con los Novella y Wyld. Por los apellidos mencionados podemos observar que reúne a la mayor parte de las élites económicas, agroexportadores de café y azúcar: Falla, Cofiño, Herrera, Arrivillaga, Alejos; industriales: Novella, Paiz, Castillo Lara y Castillo Love, Herrera; y capital financiero: Falla, Ariz, Arrivillaga, Aguirre, Saravia, Matheu, Castillo Love.26

Una vez elaborado este estudio prosopográfico de la familia Díaz Durán nos preguntamos ¿qué papel desempeñó esta red familiar a lo largo de estos tres siglos y en qué contribuyeron en el proceso de modernización para que la cataloguemos como élite dirigente y modernizante?

En primer lugar, ha sido una red familiar influyente en la esfera político-diplomática y en el ámbito económico y militar desde el siglo XVI, a través de figuras como Cerrato, Lara Morgrovejo, pasando por personajes como Joaquín Díaz Durán y Aguilar, en el siglo XIX, hasta llegar a la actualidad, con Fernando Andrade Díaz Durán. En la profusión de intelectuales orgánicos solo compiten 
con la red familiar de los Aycinena-Beltranena, pero con un perfil más liberal y modernizante.

Conjuraron desde los inicios de su ubicación en la región la actividad militar y la económica, aspecto que cobrará una gran relevancia durante los periodos de crisis y militarización del Estado guatemalteco, con sus enlaces e infuencias dentro de la casta militar. Recordemos que el fundador, Bernardo Durán fue capitán de la Corona española, Francisco Durán y Hernandez Capitán de ingenieria en el siglo XVIII, Agustín Díaz Durán y Lara Coronel, Joaquín Díaz Durán y Durán, Teniente Coronel y jefe político de Sacatepéquez y Guatemala durante el período de la revolución liberal. Octavio Santín Durán Capitán y gobernador del Quiché en 1945. Todos ellos poseían unas biografías con un cierto carácter liberal y reformista. A su vez emparentaron con la familia Ariz de Quezaltenanago con una clara tradición militar. Su trayectoria militar se asemeja a la red familiar de los Arzú, pero de componente más modernizante y progresista.

El aspecto más relevante estaba centrado en sus actividades económicas y político- diplomáticas. En el ámbito económico estuvieron vinculados a la agricultura y al comercio, ejemplo de empresario agrícola modernizante en su época fue Cirilo Díaz Durán, quien a mediados del siglo XIX, introdujo el cultivo del café en las fincas de La Antigua: Pavón y Santa Lucía y Anexos, El Pintado y Cabrejo. Sus antepasados habían cultivado añil, caña y azucar. Ya a finales del XIX, la familia introduce una incipiente industria de ladrillo y polvora y en la actualidad las fincas de la familia son uno de los modelos de mayor tecnificación y de mayor producción de café de la región antigüeña.

Los hermanos Rodolfo y Fernando Andrade Díaz Durán, a partir de 1960, diversifican su producción hacia cultivos no tradicionales como flores y legumbres y transfieren parte de su capital hacia el comercio y las finanzas fundando una Casa de agroexportación, cadenas de hipermercados y varios bancos: el Banco del Quetzal en 1985 y el Banco del Istmo, en 1994, con capital mexicano. Ello les permite incorporarse a la nueva fase de globalización de la economía.

Otro ejemplo de familias que diversifican su producción, mo- 
dernizan sus industrias, incorporan alta tecnología y se insertan en el proceso de globalización son los Castillo Lara y Castillo Monge, los Novella, Botrán y Gutiérrez.

No obstante, el ámbito más importante de su actividad estaba centrado en su participación político-diplomática y en el ámbito cultural y académico. Resultan innumerables las participaciones en la política de esta familia, cabe destacar a Domigo Durán y Hernández, Regidor del Ayuntamiento de San Salvador que participó activamente en el movimiento independentista de 1821. Don Joaquín Díaz Durán y Aguilar, del que ya hemos hablado extensamente, así como sus dos hermanos, Mariano y Manuel, participaron activamente en la Federación Centroamericana y en el movimiento Unionista. Ambos ocuparon cargos de relevancia como Ministros y Secretarios de Estado y lucharon activamente por la Unión de Provincias de Centro América. Carlos Martínez Durán, Ministro de Educación, Rector de la Universidad de San Carlos en 1945 y 1958, Fernando Andrade Díaz Durán, Ministro de Asuntos Exteriores en 1983, Representante de Guatemala ante la OEA, en 1985, Representante de Guatemala ante Naciones Unidas en 1987, candidato a la presidencia en las elecciones de 1990 y asesor del Vicepresidente Arturo Herbruger durante el actual gobierno de Ramiro de León Carpio.

En el ámbito académico y de la ciencia también jugaron un papel relevante por su contribución a la Universidad, promovieron en el siglo XVIII la fundación de las Sociedades Económicas de Amigos del País en El Salvador y Guatemala y por su formación académica en el extranjero introdujeron innovaciones en el campo científico y tecnológico. Cabe destacar la labor de Carlos Martínez Durán, Miguel Camacho y Díaz Durán, Constantino Díaz Durán y Matheu, Ramón Aceña Díaz Durán. José Constantino Díaz Durán y Matheu, miembro e la Sociedad de Geografía e Historia de Guatemala, Carlos Manuel Pellecer Díaz Durán, diplomático, escritor y periodista, hombre que militó en las filas de la izquierda, en el PGT, pasando después a hacerlo en la extrema derecha. Aceña Durán, escritor, periodista y poeta, Carlos Gándara Díaz Durán, periodista, escritor y hombre público, director del " Diario de Centroamérica" y fundador del "El Imparcial". 
En el ámbito académico y de la ciencia participaron activamente otras redes como los Aycinena, Beltranena y Arzú, con personajes ilustres como Juan Jose Aycinena y Piñol, Mariano Beltranena y LLano, Juan Fermín Aycinena y Aycinena, Antonio Batres Jaúregui y José Batres.

La diversificación de esta red familiar que copa casi todos los espacios de la sociedad civil, su flexibilidad y capacidad de mutación en momentos de crisis política y económica, así como su enorme capacidad para establecer alianzas matrimoniales y de negocios interoligárquicas le permiten situarse desde el principio en el bloque hegemónico. Pero no sólo forman parte de la élite de poder, sino que tienen una importante participación en las tareas de gobierno y poseen una importante capacidad de influencia política por la constelación de redes familiares que logran aglutinar. Por su formación académica y política, por su talante liberal y laico, por su tradición político-diplomática y tal vez por su menor provincialismo, debido a sus constantes viajes a Europa y al extranjero, consideramos que podemos catalogar a esta red familiar como élite modernizante porque a lo largo de su trayectoria político social, coadyuva, impulsa o acompaña los procesos de modernización y posee una visión más dinámica y abierta de la estructura social. Tal vez el caso de Fernando Andrade Díaz Durán sea el más paradójico, como veremos a continuación.

2. Los Díaz Durán y la recomposición del bloque dominante.(1985-1990)

F 1 triunfo de la revolución sandinista y la conformación de un Enuevo bloque histórico marcan una nueva pauta para el resto de la región y provocan fuertes convulsiones sociales y políticas en toda la estructura social.

Podemos afirmar que en Guatemala se produce un vacío de poder y un intento de transformación radical de la sociedad y del bloque histórico de 1979 a 1983, período en el que la crisis económica y el vacío de poder se agudizan sin que las clases subalternas y sus vanguardias, URNG, Unidad Revolucionaria Nacional Guatemaleca, pudieran cambiar el rumbo de la historia y modificar la correlación de fuerzas en el seno del poder. 
A partir de, 1981, en Honduras, de 1982, en El Salvador y de 1983, en Guatemala, se inició una recomposición del bloque hegemónico que va a dar origen a procesos de apertura política e intentos de democratización y consolidación de incipientes Estados de dèrécho, mediante la restauración de procesos electorales no viciados, retorno de gobiernos civiles de centro, aplicación de reformas sociales y reactivación de procesos regionales, que permitieron encontrar nuevas salidas a la crisis nacional y regional.

Cada país del área va a buscar distintos mecanismos sociales y políticos de recomposición del bloque hegemónico y de alternativa a la crisis regional, pero en los tres países de mayores conflictos socio-políticos, se van a producir cambios similares: procesos electorales no viciados con amplia participación popular; instauración de gobiernos civiles; aparente desplazamiento de los militares del gobierno, no del Estado; intentos de apertura política y de consolidación de un Estado de derecho; tímidas reformas sociales: agraria, fiscal, bancaria; intentos de desplazamiento de las oligarquías tradicionales y participación de nuevas fracciones de clase más modernizante; tentativas de búsqueda de una solución política a los conflictos regionales mediante la participación de Contadora; cumbres de Presidentes y reuniones regionales: Esquipulas I y II; aplicación de una nueva estrategia militar, la LIC, Guerra de Baja Intensidad; búsqueda del díalogo como solución política a los conflictos armados.

Muchos de estos puntos se dan de forma similar, con las variantes específicas en cada país, en Guatemala, El Salvador y Honduras, de 1981 a 1990 y Nicaragua compartirá algunas de las premisas señaladas, sobre todo aquellas relacionadas a la búsqueda del diálogo y negociación, como fórmula para resolver sus conflictos internos.

Ahora bien, la primera pregunta que surge ante este fenómeno de remodelación de la clase dominante es: ¿por qué la crisis de dominación oligárquica no condujo a una ruptura del bloque histórico, sino a un reforzamiento de la oligarquía centroamericana; y ¿cómo esta clase pudo reconstituirse después de la década perdida y salir casi idemne de la crisis de dominación?

A nuestro juicio la clave de la respuesta se encuentra en el he- 
cho de que las pugnas y fraccionamientos de la oligarquía, que se produjeron a lo largo de los años setenta y parte de los ochenta, se dieron en el ámbito político por el control de la hegemonia, pero en el plano económico; a pesar de los avatares de la década, de la crisis económica, de la guerra y del vacío de poder, su infraestructura económica - sus medios de producción y su actividad productiva- se mantuvo intacta o al menos no fue afectada sustancialmente. Es más, nos atrevemos a afirmar, que en algunos países como Guatemala, El Salvador y Honduras, salió reforzada.27

La diversificación de la producción, la ampliación de su actividad productiva del agro a la industria y a las finanzas, una mayor modemización y tecnificación en el campo y en sus industrias e, incluso, el propio desarrollo del conflicto bélico, favorecieron sus negocios y no afectaron a la producción, ni la debilitaron económicamente, al contrario, salió fortalecida. 28

Este proceso de acumulación económica en tiempos de guerra, de modernización y tecnificación, obligada por la coyuntura política de defensa a ultranza de sus intereses por el temor a perderlos, le permite, a mediados de la década de los ochenta, reconstituirse como clase politica y lanzarse de nuevo a la toma del poder con un proyecto político propio nacional y regional.

De ahí que se lance a la conquista del poder y a imponer una nueva hegemonía recomponiendo el bloque dominante y presentándose como empresarios modemizantes. Para ello se hacía necesario aceptar nuevas premisas de dominación: un modelo de transición democrática, una finalización de los conflictos bélicos a través del diálogo y la negociación y la reactivación del MCCA, una aplicación de políticas neoliberales de "ajuste económico" y la creación de mecanismos jurídico-financieros que les permitieran insertarse en el proceso de globalización.

Generalmente, estos procesos de transición fueron llevados a cabo por hombres pertenencientes a su clase, lo que hemos denominado los intelectuales orgánicos de la clase dominante. En Guatemala, Fernando Andrade Díaz Durán y Alvaro Castillo Monge, en Honduras Rafael Callejas y Rosenthal, en El Salvador, Roberto Murray Meza y Alfredo Cristiani, en Nicaragua Antonio Lacayo Oyanguren y la familia Chamoro. Estos personajes son miembros 
de las principales redes familiares, reúnen, a través de sus alianzas familiares y de negocios, a las fracciones más modernizantes de la clase dominante y por su capacidad política, económica e intelectual expresan el sentir de su clase.

Durante el período de la transición política, estos personajes van elaborando un nuevo discurso politico-ideológico de corte reformista y neoliberal, apoyando ciertas reformas políticas y económicas para modernizar el Estado y el mercado, reactivando los procesos de integración centroamericana y creando mecanismos financieros para insertarse en la nueva fase de la globalización. Esta " nueva derecha" o " derecha renovada", como la denomina Sarti o Tapia29. Esta oligarquía mimetizada, o derecha ilustrada, como preferimos llamarle nosotros, va a ir constituyendo nuevos partidos, como ARENA; UCN, MAS, PAN, UNO, o renovando los tradicionales como PUSC y PN, y va a plantear un discurso neoliberal de ajuste estructural, acompañado de un apoyo a los procesos de transición democrática y de integración política y económica regional y de una defensa de la consolidación de un Estado de derecho que, unas décadas antes, ellos habían abortado apoyando a regímenes de facto.

Si comparamos los programas electorales de todos estos partidos, observaremos las enormes similitudes en todos ellos. Cabe destacar las grandes coincidencias entre el progama de ARENA y el del PAN, o del PN con el PUSC, todos ellos haciendo énfasis en el ajuste estructural, en la modernización y reestructuración del Estado, en el apoyo a ciertas reformas sociales y a una política de derechos humanos. En los países con serios conflictos bélicos, el énfasis está en el proceso de diálogo y pacificación, en la creación de un nuevo modelo de desarrollo agrícola, basado en la reorientación de las exportaciones hacia productos no tradicionales y en la reactivación de mecanismos de integración regional. Frente a los problemas sociales básicos como el desempleo, la distribución de la tierra, la inflación, proponen una política de mejoras energéticas, de desarrollo agrícola moderno y creación de empleo y de protección del medio ambiente.30

Así pues, coincidimos con la afirmación de Sarti y de Tapia, que la crisis de dominación oligárquica no conllevó a un desplaza- 
miento de la oligarquía, porque no se llegó a producir una renovación burguesa, como cabía esperar, sino un reforzamiento y reconstitución de la oligarquía, en torno a las redes familiares tradicionales, que se presentan con un discurso y un estilo más modernizante $y$ tolerante, que permite pensar en que se ha producido un cambio de dominación, pero que ideológicamente, sus presupuestos económicos y sociales continúan invariables. A este proceso de mutación le hemos denominado " la metamorfosis de las oligarquias", en la medida en que se produce un cambio de imagen, pero no de dominación, se modifica la correlación de fuerzas al interior del bloque dominante, pero sin rupturas dentro del mismo, se renuevan ciertas élites, pero sin que los sectores tradicionales pierdan su cuota de poder. Lo que no parece variar es la forma de dominio y el tipo de legitimación basada en relaciones clientelares y de subordinación paternalista, en donde las clases subalternas no parecen tener cabida como ciudadanos y en donde el racismo continúa operando como un factor sustancial de legitimación y de diferenciación social.

El caso de Guatemala resulta paradigmático respecto al patron de reciclaje de las redes familiares oligárquicas.

La oligarquía guatemalteca obedece al patrón conservador, tradicional y mas endogámico de América Central, probablemente por la solidez y el entramado de sus redes familiares y por ser la oligarquía más poderosa de la región y también por la importante presencia de población indígena, lo que les añade un componente racista muy fuerte respecto a las demás. Durante el período de crisis oligárquica no abandonaron el poder, ni vieron seriamente en peligro sus propiedades.

Durante las últimas décadas, en las que apostaron por la vía autoritaria y contrainsurgente, y delegaron en los militares ciertas tareas políticas, siempre se reservaron dos o tres ministerios claves como agricultura, economía, finanzas y en algunas ocasiones, el Ministerio de Asuntos Exteriores. Nombres como Arenales Catalán, García Granados, Herrera Ibarguen, Andrade Díaz Durán, pertenecian a estas redes familiares.

A principios de la década de los 80 , se produjo una crisis de dominación, una falta de consenso sobre el modelo económico y el 
proyecto político a seguir, lo que generó fricciones al interior del bloque dominante, cuya máxima expresión tuvo lugar durante los gobiernos militares de Lucas García y Ríos Montt, de 1978 a 1983.

Con el golpe de Estado de Mejía Víctores, se inicia la remodelación del bloque en el poder y se modifica la correlación interna de fuerzas de la oligarquía, que presenta un nuevo proyecto político nacional y regional. A nuestro juicio, este proceso de transición política fue liderado por uno de los intelectuales orgánicos de la clase dominante, Fernando Andrade Díaz Durán, por sus relaciones con las principales fracciones de la oligarquía nacional y centroamericana, sus buenas relaciones con un sector de los militares y el apoyo de ciertos lobbys norteamericanos, pudo iniciar la remodelación de la clase dominante, llevar a cabo, en 1984, la celebración de elecciones a la Asamblea Constituyente y un año más tarde, convocar elecciones generales y entregar el poder a un civil. Fueron las redes familiares vinculadas a la familia de los Andrade Díaz Durán, las que apoyaron este proyecto. Entre ellas podemos citar a los Castillo Monge, Botrán, Castillo Love, Vanderhaens, Falla, Cofiño, Novella, Herrera, Paiz Andrade, Vila, en su mayoría pertenecientes a las fracciones de clase anteriormente citadas y con estrechas relaciones familiares y de negocios con los Díaz Durán.

Fernando Andrade Díaz Durán juega un papel importante como intelectual orgánico del sistema y consideramos que es el artífice de la política de alianzas que se producen en el interior del bloque histórico, con los otros factores de poder y de la política internacional que permitió a Guatemala romper el aislamiento internacional en que se encontraba desde 1978 e iniciar el proceso de apertura política y retorno a la insitucionalidad. Como Ministro de Asuntos Exteriores durante el régimen de Mejía Víctores, obtuvo importantes logros en política exterior: Consiguió abrir espacios en organismos internacionales, como Naciones Unidas, OEA, a pesar de las innumerables condenas que el régimen de Mejía Víctores recibía en estos organismos, reanudó relaciones diplomáticas con España, rotas desde el asalto de la Embajada de España en 1981. Llevó a cabo en Centroamerica una política de neutralidad en el conflicto regional, propugnando una posición de apoyo a Contadora y de reactivacion de la integración económica y política regional. Logró que Guatemala participara en las reuniones de San José I y 
II. Mejoró las relaciones diplomáticas con México con el tema de los refugiados.

Todo ello le proporcionó a Guatemala espacios internacionales que se habían cerrado durante décadas por la constante violación de los derechos humanos y credibilidad regional e internacional que antes no había tenido, a pesar de que el régimen militar de Mejía Víctores no había variado, la violación de los derechos humanos persistía e incluso en algunos sectores se incrementaba y ninguna de las libertades fundamentales se habian puesto en práctica. En otras palabras, sentó las bases para que se produjera un proceso de transición democrática, sin que la élite de poder se viera afectada, favoreciendo a los grupos mas modernizantes del momento.

\section{Las elecciones de 1990 y el retorno de la élite de poder por la vía de las urnas.}

L

as expectativas que despertó el gobierno de Vinicio Cerezo pronto se vieron frustradas por la falta de capacidad de maniobra del presidente, los innumerables conatos de golpe de estado y la corrupción desmedida de su gobierno. Ello produjo una retirada de los apoyos iniciales y un proceso de reconstitución en torno a nuevos partidos como el MAS y el PAN, especialmente el segundo, por estar liderado por un miembro de su propia red, Alvaro Arzú Irigoyen. Fernando Andrade Díaz Durán no supo buscar el apoyo en partidos de nuevo cuño y los tradicionales con los que contó, PR y PNR, estaban demasiado desgastados y deslegitimados por los fraudes electorales del pasado y por su política pactista con los militares.

Contrariamente al caso de El Salvador, en donde ARENA logró aglutinar a la mayor parte del núcleo oligárquico, probablemente porque el nivel de crisis económica y confrontación bélica era mayor y la necesidad de cohesión y respuesta unificada indispensable. En Guatemala, los apoyos de la oligarquía estaban divididos en tres partidos, UCN, MAS y PAN. Posiblemente, este último contó con mayor respaldo de las principales redes -Aycinena, Beltranena, Batres, Castillo, Asturias, Herrera, Berger, Alejos, Arzú por tener el mayor número de miembros pertenecientes a las re- 
des familiares y por el apoyo que el partido tenía la elite dirigente salvadoreña.

Sin embargo el MAS, a pesar de contar con otro sector de la oligarquia, aquel que se había convertido al evangelismo, los Falla, Castillo, Bianchi, Alejos, Arimany, Botrán, tenía además el 35\% del electorado de filiación evangélica, que al no votar a Ríos Montt, pasó su voto a otro evangélico, Jorge Serrano Elías. Esta nueva base de apoyo pentecostalista, permitió al MAS situarse en segunda posición, en la primera ronda y en primera posición en la segunda, gracias a la alianza con el PAN, cuyos votos sumaban en torno al 35\% del electorado.

Como podemos observar por algunos diagramas presentados a lo largo del trabajo, los miembros de la oligarquía que formaron parte del Gabinete ministerial del presidente Serrano Elías, del Consejo Específico de la Presidencia y de la Alcaldía Municipal de Guatemala, sumaban más de diecisiete cargos de relevancia entre ministros, vice-ministros, asesores y consultores específicos. Casi todos ellos vinculados a través de lazos consanguíneos o de matrimonio y en su mayor parte nucleados en torno a la familia Arzú, Aycinena Beltranena y Díaz Durán. El caso más evidente lo presentaban seis ministros del gabinete: Acisclo Valladares Molina Aycinena es primo de Maria Luisa Beltranena Valladares, quienes a su vez está emparentados con los Arzú Aguirre Beltranena y con los Aycinena Irigoyen, directamente realcionados con la red de los Arzú Romá y Arzú Batres, a través de los Rubio y Alvarez de la Piloña, quienes a su vez poseen estrechas relaciones de parentesco con los Alvarez de las Asturias, Carrera y Dorión. (Ver diagrama n. 5 de los Beltranena Arzú).

El Ministro de economía Jose Luis Mirón Aguilar, está vinculado a la red de los Matheu Ariza, quienes a su vez emparentan a lo largo del siglo XIX y XX con los Diaz Durán, Cofiño, Alejos y Herrera Dorión y en la actualidad poseen estrechas relaciones de parentesco y de negocios con los Alejos, Herrera y Cordón; el Ministro de Agricultura Adolfo Boppel Carrera, se encuentra vinculado a las familias anteriormente mencionadas, todas ellos pertenecientes al sector agroexportador tradicional nucleado en torno al cultivo del café.31 
Resulta curioso o al menos novedoso, en el caso del gabinete del Presidente Serrano Elías, miembro de la secta Shaddai, conocer cómo y en qué términos se produjo la articulación de un bloque tan heterogéneo, partiendo de la base de la profunda confesionalidad católica de un sector del núcleo oligárquico que casi raya en el integrismo, con otro sector evangélico pentecostalista con altos índices de intransigencia y fanatismo, pero que sumaban alrededor del $25 \%$ de la población guatemalteca. A ello habría que añadirle la ingenuidad o la precipitación en la participación de un sector social-demócrata, que no llegó a sumar el 3\% de la votación, pero que colaboró con su presencia en el gobierno, ocupando varios ministerios y viceministerios. Esta amalgama logró una cohesión e integración frágil e inestable debido a que los pactos interelitarios eran coyunturales y basados exclusivamente en términos electorales y no en programas políticos o puntos de consenso y convergencia, que permitieran un asentamiento estable y posibilitaran la incorporación de nuevos actores sociales, que dieran juego político al nuevo sistema de dominación. Una vez más se habían cambiado las personas, pero no la forma de dominación; una vez más la élite de poder había mostrado su habilidad para incorporar y fagocitar todo aquello que le pudiera generar riesgo 0 inestabilidad en el ejercicio del poder. 32

Con el intento de autogolpe del presidente Serrano, en mayo de 1993, todos los actores sociales se movilizan para evitar su consumación y por primera vez en la historia contemporánea guatemalteca, la oligarquía y sus representaciones gremiales, se oponen al golpe y forman la Instancia Nacional de Consenso, para evitar el autogolpe. Por primera vez la oligarquía trata de formar un frente único con la sociedad civil y generar un consenso, un pacto social para salir de la crisis institucional. En este procesos colaboraron casi todos los sectores sociales, jugando un papel decisivo los medios de comunicación vincuilados a las élites modernizantes como los Gutiérrez, Castillo Monge, Toriello etc. Una vez elegido popularmente Ramiro de León Carpio y Arturo Herbruger como vicepresidente, Fernando Andrade Díaz Durán aparece de nuevo en la escena política como asesor del Vicepresidente, colaborando activamente en el pacto de renovación de noviembre de 1993. Su renuncia en abril de 1994 apareció como un intento de complot contra el presidente. 
4. La aplicación del modelo de redes familiares para la comprensión de la historia social y política centroamericana.

Dodemos observar como el análisis prosopográfico de la familia 1 Diaz Durán, nos sirve de hilo conductor para comprender parte de la historia política de Guatemala. El análisis diacrónico y sincrónico de esta familia o de un conjunto de familias "notables" nos permite analizar el comportamiento político del bloque de poder, sus estrategias y manipulaciones para legitimarse en el poder y su perdurabilidad a lo largo de varios siglos, pudiendo afirmar, sin lugar a dudas de que estas redes familiares se constituyen en estructuras de larga duración. Para completar nuestro estudio hubiera hecho falta un análisis detallado del pensamiento político de uno o varios miembros de la red para conocer su incidencia en el imaginario político y social de su clase.

Recapitulando el análisis prosopográfico de la familia Díaz Durán podemos deducir que:

1. La familia Díaz Durán pertenece a las familias de conquistadores y primeros pobladores de Guatemala por su vinculación con el conquistador Sancho de Barahona. Se asientan en el siglo XVII en El Salvador y pronto ocupan cargos públicos de relevancia. Desde el inicio emparentan con la familias más poderosas el El Salvador Núñez Guzmán, Navas, Escalante y Arce y con poderosas familias guatemaltecas, Herrera, Díaz del Castillo, Lara, Molina y Rodil.

Es a raíz de su traslado a Guatemala, cuando empiezan a ejercer influencia en el ámbito político e intelectual y a ampliar su capital a través de la compra de haciendas de añil, ganado y café en La Antigua Guatemala. El hecho de ubicarse en la Antigua, también les circuscribe a un espacio regional determinado con características propias a nivel de la producción y les enlaza con el sector de la oligarquía guatemalteca más modernizante y tecnificado.

2. En la familia Diaz Durán, existe una larga vocación político-dipomática e intelectual. Varios antepasados ocuparon cargos de relevancia en la política nacional y regional. Esta familia, probablemente por sus origenes salvadoreños y por los entronques que establece con otras familias hondureñas y nicaragüenses, po- 
see una larga tradición regional y federativa. Muchos de sus parientes ocuparon cargos en El Salvador, otros fueron importantes miembros de la Federación y del Partido Unionista. Esta larga tradición federativa y unionista a nivel centroamericano, así como sus lazos familiares con otras familias de la región, se plasma en el pensamiento de Fernando Andrade Diaz Durán, quien plantea por primera vez la política de neutralidad en la región, proyecta la constitución del Parlamento Centroamericano y abre relaciones económicas y políticas con la $\mathrm{CEE}$, colaborando activamente con Contadora y en las reuniones de San José.

Sus vinculos con el Salvador, Honduras y con Nicaragua le llevan a tener una buena relación con estos gobiernos; sus antecedentes históricos familiares y sus enlaces regionales, le convierten en un político de gran prestigio a nivel regional.

En comparación con los Aycinena y los Arzú, podemos decir que ambas son redes extensas que van más allá del ámbito nacional y elaboran una política con proyección regional. Ambas familias poseen grandes intelectuales y políticos en sus filas y generalmente juegan un papel determinante en coyunturas de crisis como lo fue el periodo de la Independencia, la Federación o el régimen conservador, de ahí la relevancia de los intelectuales orgánicos de la clase dominante. La diferencia básica con los Aycinena, que sin duda ha sido la red con mayor incidencia política en los siglos XVIII y XDX, es su perfil conservador y poco modernizante y la influencia religiosa de casi todos sus intelectuales orgánicos civiles y religiosos. Otro elemento que les diferencia es que los Aycinena entran en declive a principios del siglo $X X$ y se recuperan políticamente a finales del siglo, en las elecciones de 1990, mientras que los Díaz Durán tienen una presencia más constante y permanente a lo largo de todo el siglo $X X$, siendo más notoria y clave su participación en las últimas décadas.

Sin duda, ambas familias representan el prototipo de élite dominante y dirigente ilustrada que introduce la Modernidad en Guatemala, ambas son redes familiares que, en periodo de crisis de dominación copan los espacios políticos y ocupa el lugar del Estado para después retornar a la sociedad civil desde donde ejercen su influencia. 
A diferencia de otras familias, como los Arzú o los Urruela, existe un mayor laicismo en la familia Díaz Durán. En esta familia hay una escasez de religiosos y una abundancia de profesionales, académicos y políticos, pero sobre todo, volvemos a insistir hay una abundancia de intelectuales orgánicos que cabalgan en la Modernidad en distintos períodos históricos.

Sin duda alguna la red de los Díaz Durán y su amplia alianza interoligárquica colaboró de forma decisiva en el proceso de transición democrática y en la recomposición del bloque hegemónico contribuyendo a salir de la crisis orgánica en que ésta se encontraba desde 1980. Posibilitó que sectores más modernizantes de la oligarquía se hiciesen con la hegemonia y apoyasen el proceso de modernización económica y política de la sociedad guatemalteca, contribuyó a que en las elecciones de 1990 pudiera retornar al poder las antiguas redes familiares oligárquicas mimetizadas de empresarios modernizantes y colaboró en impedir el golpe de Estado de Serrano Elías. A pesar del fracaso en la contienda electoral de 1990 por el tipo de partidos que le apoyaron, ello no supone que en las próximas elecciones vuelva a intentar participar, con partidos políticos de nuevo cuño o en proyectos de convergencia más amplios.

3. Resulta evidente, una vez realizados varios trabajos prosopográficos de la familia Diaz Durán y de otras familias centroamericanas como los Chamorro, Lacayo, Valle, Meza Ayau, Escalante, Arzú, Aycinena, Beltranena, confirmar la pervivencia de estas redes familiares en el bloque de poder en América Central. El caso de los Díaz Durán no es exclusivo y la composición oligárquica de los gobiernos de Guatemala, El Salvador Honduras y Nicaragua, asi parecen indicarlo.

Si bien es cierto que el proyecto político de esta red familiar, así como de las redes primarias y secundarias que le acompañan es de carácter modernizante, en aras a la preservación de su estirpe y con el fin de insertarse en el nuevo orden económico mundial, y para ello resulta indispensable apoyar procesos de democratización, modernizar el Estado, aplicar una política neoliberal y reparar las enormes desigualdades mediante el pago de una deuda social. Lo que también resulta evidente es que su imaginario so- 
cial, respecto a otros grupos socio-raciales, especialmente el indígena, continúa siendo profundamente endogámico, racista y elitista, sin aceptar la imperiosa necesidad histórica de configurar un tipo de Estado democrático que represente los intereses del conjunto de identidades básicas, especialmente de la población indígena cuya presencia real y protagonismo histórico resulta insoslayable.

Podriamos concluir afirmando que, estas redes de larga duración subsisten por los enlaces matrimoniales exitosos, por las alianzas de negocios, por la expansión regional y por la diversificación de su producción en períodos de crisis económica y en el momento actual, por su inserción en el mercado internacional de capitales. Se legitiman o logran consolidarse porque su poder emerge de la sociedad civil en donde poseen un complejo entramado de relaciones sociales verticales y horizontales, de alianzas paritarias y subalternas y de intereses de mercado y porque en periodos de vacío de poder ocupan la sociedad política, sustituyen a los partidos y ejecutan ciertas funciones que corresponderían al Estado de derecho, pero que ante su fragilidad y escasa legitimidad, son estas redes familiares las que ocupan ese lugar. De este modo las redes familiares se convierten en élites de poder y en algunas ocasiones en élites dirigentes y/o gobernantes. Este tránsito no podría ser posible sin el apoyo de sus propios intelectuales orgánicos que son los encargados de establecer esas alianzas y de proporcionar a su red familiar los intrumentos de cambio necesarios para subsistir en el bloque hegemónico.

Esta amalgama entre sociedad política y sociedad civil no sería posible sin la presencia de estos intelectuales de la clase dominante que aseguran de este modo la pervivencia de su linaje, pero que no logran despojarse de su forma de dominación tradicional y clientelar, ni de su imaginario social elitista y etnocéntrico propio del "estilo oligárquico". Su metamorfosis es solo parcial y obedece más a las presiones externas y a los cambios imperiosos del orden internacional que a sus estructuras mentales que permanecen esclerotizadas y cerradas ante su propia realidad y ante el resto de su colectividad. Para ellos Guatemala sigue siendo un bello paisaje, que no quieren transformar en paisanaje, ni colaborar en la transformación de sus vecinos y "subalternos", en ciudadanos con los mismos derechos y deberes. 
Por último querríamos terminar nuestra ponencia, sugiriendo nuevas vías teorico-metodológicas de aproximación a la historia política y social centroamericana, pues si bien es cierto que el estudio de las élites de poder no permite un conocimiento global de la sociedad, sino únicamente el análisis de un sector minoritario, pero influyente de la misma, no es menos cierto que el conocimiento profundo de este sector nos permite comprender mejor sus estrategias, sus pactos interelitarios y su proyecto social y político.

Nosotros abogamos por un estudio interdisciplinario de largo alcance en donde se conjuguen cinco variables para la comprensión de la estructura social y política centroamericana. Estas cinco variables: élites, la variable étnica, la de género y los movimientos sociales y revolucionarios. Estaría enmarcado en una categoría global de clase social sin la cual los analisis parciales de las otras variables quedarían descontextualizadas.

La articulación de estas cinco variables y su relación con el Estado nos permitiria tener una visión más global y una comprensión más objetiva y precisa de los diferentes actores sociales y políticos, de la articulación entre la sociedad civil y la politica y de la relación de estas esferas con el Estado. Ello nos permitiría elaborar políticas de consenso o de convergencia de largo alcance en donde el Estado se convirtiera en el mediador o interlocutor de las diferentes identidades básicas y en el gestos de las reivindicaciones del conjunto de la colectividad.

\section{Notas}

1. Las compilaciones más completas sobre estudios de la familia como línea historiográfica son los trabajos de KUSNESOF, E. y OPPENHEIMER, R. " The family and society nineteeth century Latin American: An historiografical introduction", Jourmal of the family, fall 1985, p: 215-234. Así como el articulo de TILLY, L. y COHEN M., "Does the family have history ?", Social Science History „, vol 6 n. 2, spring 1982, p: 131-179. Este último desde una perspectiva diferente a la nuestra. El artículo de BALMORI, D., VOSS, S. y WORTMAN, M., sobre "La red familiar en la literatura histórica" en su libro, Las alianzas de familias y la formación del país, México, FCE, 1990, es una de las recopilaciones más completas sobre el estudio de la familia como unidad social e histórica de análisis. Un repaso de las últimas publicaciones sobre el tema lo encontramos en KUSNESOF, E., "The history of the family in Latin America: A critique of recent work", en LARR, 29, n. 4. 1993, p: 254-23.

2. Los trabajos más relevantes de las últimas décadas en esta dirección son los 
de RAMIREZ, S., Patriarcas provinciales, tenencia de la tierre y la economín del poder en el Perí colonial, Madrid, Alianza América, 1991. LOCKHART, J., El Mundo hispano peruano 1532-1560, México, FCE, 1982, DE LA PEN̄A, J., Oligarquía y propieded en Nueaa España 1550-1624, México. FCE, 1983 y ORTIZ DE LA TABLA DUCASSE, J., Los encomenderos de Quito 1534-1660, Origen y eoolución de una élite colonial, Escuela de Estudios Hispanoamericanos, CSIC, Sevilla 1993. BAHAMONDE, A. y CAYUELA J. Hecer las Américas, les élites coloniales españoles en el siglo XIX, Madrid, Alianza América, 1992.

3. Sobre la importancia del Cabildo u otros instituciones de poder local véase los trabajos de LOCKHART, J, El Mundo hispano, LIHER, R. Ayuntamiento y oligarquía en Puebla, 1787-1810, México, FCE, 1976, WEBRE, S., La sociedad colonial en Guatemala: estudios regionales y locales , Antigua Guatemala, CIRMA, 1989, así como GONZALEZ MUÑOZ, V. y MARTINEZ ORTEGA A. I., Cabildos y élites capitulares en Yucatón, Escuela de Estudios Hispanoamericanos de Sevilla, CSIC, Sevilla, 1989.

4. Sobre la importancia del factor socio-racial en la configuración de la estructura social latinoamericana, el pionero ha sido M. MÖRNER, La mezcla de razas en la Historia de América Latina, Paidos, Buenos Aires, 1969; así como Estado, Razas y cambio social en la Hispanoamérica Colonial , México, Septentas, 1974. El trabajo de LIPSCHUTZ, A., El problemia racial en la conquiste de América, México, Siglo XXI, 1975 fue bastante revelador. Posteriormente se han elaborado irinumerables estudios específicos, entre los que cabe destacar el de CHANCE, K J., Race and class in colonial Oaxaca, Standford University Press, California, 1978, ISRAEL, J.I., Razas clases sociales y oida política en el México colonial, 16101670, México FCE, 1980, SEED P., " Social Dimension of race in Mexico city, 1753" en $H A H R$, vol. 62, 1982, p: 569-606, CASAUS ARZU, M. Guatemala Linaje y Racismo, San José, Costa Rica, Flacso, 1992.

5. El concepto de " notables" es utilizado por BALMORI, VOSS y WORTMAN, para referirse a aquellas familias que por su influencia económica y política y por su incidencia en los acontecimientos históricos poseen una " notabilidad"; DE LA TABLA DUCASSE, utiliza para referirse a este tipo de familias el adjetivo de" beneméritas", porque éstas se consideraban dignas de recibir mercedes de la Corona por sus méritos durante la conquista durante el proceso de poblamiento de América Latina. Nosotros preferimos utilizar un concepto más ecléctico de primarias y secundarias, por considerar que en cada siglo o período histórico, existían una o dos familias preeminentes en torno a las cuales se situaban una serie de familias secundarias en importancia económica y en prestigio que establecían alianzas matrimoniales y relaciones de negocios con las principales y giraban en tomo a estas constelaciones familiares formando un sólido entramado social.

6. Consideramos fundamental la introducción del concepto de intelectual orgánico de Gramsci con el fin de estudiar aquellos personajes históricos vinculados orgánicamente a su clase, red familiar o la élite de poder, que por su capacidad de alianzas, su correlación de fuerzas y su papel en los procesos de transición, fueron capaces de elaborar una ideología coherente, un pensamiento político homogéneo que proporcionaba a su grupo una concepción del mundo que les permitia pasar de un período histórico a otro sin ruptu- 
ras, o brindaba a su clase una interpretación coherente en los momentos de crisis y vacío de poder. El trabajo de D. BRADING sobre Orbe Indiano. De le Monarquía católica a la República Criolla, FCE, México, 1992, nos parece que apunta en esta dirección.

7. Sobre el proceso de diversificación de la producción de estas familias en momentos de crisis económica los estudios más ilustrativos son los de BRADING, D., Mineros y comerciantes en el México Borbónico, México, FCE, 1980, KICKZA, J., Colonial Entrepreneurs: Families and business in Bourbon Mexico city, Alburquerque, 1983. LEVI, DARREL, E., A familia Prado, Sao Paulo, Cultura 70, 1977 y CERUTTI M., y VELLINGA M., Burguesías $e$ Industrias en América Latina y Europa Meridional, Madrid, Alianza América, 1989. Todos ellos hacen énfasis en las familias adscritas a un sector de la producción: minas, tierras, comercio y su capacidad de reconversión en época de crisis. BAHAMONDE, A. y CAYUELA, J., Hacer las Américas, las élites coloniales cubanas en el siglo XIX, Alianza América, Madrid, 1992.

8. El libro de Balmori, Voss y Wortman es el primero en elaborar un manco teórico acerca del funcionamiento histórico de las familias como redes de poder de larga duración, como corporaciones económicas y élites políticas que suplen en momentos determinadas al Estado y ocupan su lugar. También introducen el análisis generacional, para analizar las redes familiares durante el siglo XVIII hasta principios del XX, análisis que ya aparece como sugerencia metodológica en Mörner en su artículo " Economica factors and stratification in colonial Spanish America with special regard to elites", en HAHR, 63, 2, 1983.

9. CASAUS ARZU M., Guatemala: Linaje y racismo, y "La metamorfosis de las oligarquías centroamericanas" en Centroamérica: Balance de la década de los 80 , Une perspectioa regional, Madrid, CEDEAL, 1993. En un estudio prosopográfico de 22 familias centroamericanas que arrancan de la fundación de Santiago de los Caballeros en 1544 y van produciéndose adiciones, en función de distintas oleadas de emigraciones vascas, alemanas etc, a lo largo de los siglos XVII, XVIII y XIX, observamos como un buen porcentaje de las que actualmente forman parte de la élite de poder proceden del período colonial y continúan ocupando un lugar preeminente en la economía y la política del pais. Véase en nuestro libro los linajes de Bemal Díaz del Castillo, Delgado de Nájera, Aycinena, Beltranena, etc. Un elevado porcentaje de ellas proceden de redes familiares vascas que se asentaron en América Central a partir del siglo XVII. Véase la tesis doctoral de Teresa García Giráldez, " La emigración vasca a Centroamérica 1750-1800. Las redes familiares como estructura de poder en Guatemala", Universidad Autónoma, Madrid, 1993.

10. Partimos del planteamiento teórico de que clase social, élite de poder y red familiar no tienen que ser necesariamente conceptos contrapuestos, sino complementarios, en la medida en que obedecen a distintos niveles de abstracción y de aprehensión de la realidad social. Que si bien, parten de líneas historiográficas contrapuestas, Pareto, Mosca, Weber versus Marx y las posteriores teorías marxianas. Existen autores y líneas de convergencia como es el caso de Weber, Mills y Domhoff desde la perspectiva de la acción individual y como es el caso de Gramsci, Sweezy, Dahl y Carmagnani desde la 
perspectiva de la acción social, y desde el estructuralismo, Levi Strauss, Burguiere y Le Goff, pueden servirnos para elaborar un marco teórico menos excluyente y dicotómico. Los intentos mejor logrados sobre la confluencia de estos conceptos en análisis empíricos los tenemos en TUTINO, J., " Power class and family men and women in the Mexican elite, 1750-1810 en The Americas XXXIX: 3, 1983, p: 359-381. VILAS, C.M., " Linajes y familias en la Nicaragua actual" en Polémica, Diciembre 1992. DE LA PEÑA, J., Oligarquía y propiedad en Nueva España 1550-1624, México FCE, 1983 y BRADING, D., Mineros y comerciantes en el México Borbónico.

11. Véase ALTMAN I., Emigrantes y sociedad, Extremadure y América en el siglo XVI, Madrid, Alianza América, 1992 p: 166-167. AAVV, Familias nodohispanas siglos XVI al XIX, México, Colegio de México 1991, especialmente los artículos de María Urquidi, Pedro Pérez Herrero y Elisabeth Kusnesof. ORTIZ DE LA TABLA DUCASSE, J., Los Encomenderos de Quito... Sobre la importancia de la familia vasca véase la tesis de Teresa García Giraldez, "La emigración vasca..."

12. Insistimos en la obra de Mörner y Lipschutz por la importancia que confiern al factor socio-racial y nos parecen fundamentales aquellos estudios que vinculan relaciones de género y raza, como STOLCKE V., Racismo y sexualidad en la Cuba colonial, Madrid Alianza América, 1992. KUSNESOF, E., " Raza, clase y.matrimonio en la Nueva España: estado actual del debate" en Familias Nooohispanas siglos XVI al XIX, p: 373-379. COUTURIER, E. " Women in a noble family: The mexican counts of Regla 1750- 1830, en Latin American Women, p: 130-149. LUNA G. L. (comp) Género, Clase y Raza en América Latina, Universidad de Barcelona, 1991.

13. Véase ORTIZ DE LA TABLA DUCASSE J., Los Encomenderos de Quito...; CASAUS ARZU, M., Guatemala Linaje y Racismo; PEIRE, J., "La manipulación de los capítulos provinciales, las élites y el imaginario socio-político colonial tardío" en Reoista de la escuela de Estudios Hispanoamericanos, Tomo L n. I 1993 y LANGUE, F., " Las élites en la América española, actitudes y mentalidades", en Boletín americanista, Universidad de Barcelona, 1992- 1993, n. $42-43$. $\mathrm{p:}$ 123-141. En general fueron mayores las alianzas y vinculaciones entre criollos y peninsulares que las pugnas o disidencias entre ambos grupos.

14. Nuestra hipótesis acerca de la fortaleza de las redes familiares por su profunda inserción en la esfera de lo civil, está sin confirmar, pero consideramos que es un buen punto de partida para futuros análisis. La mayor parte de los estudios de historiadores europeos ponen más énfasis en los aspectos funcionalistas de las redes de parentesco o clientelares que en la estructura de la red, resaltando más las redes de clientelismo que la red familiar como estructura de poder de larga duración. Merecen destacar los trabajos de LEVY PECK, L.(comp), Court patronage and corruption in Early Stuart England , Boston Unwin Hyman, 1990. GELLNER E. el all., Patrones y clientes, Barcelona, 1986. COSS P.R. "Bastard Feudalism revised" en Past and Present, n' 125, Nov. 1989, p: 26-63. Para España merece destacar los trabajos de MARTINEZ MILLAN, J., Instituciones y elites de poder en la monarquín Hispana durante el siglo-XVII, Madrid, Ed. Universidad Autónoma, 1992. 
15. Pocos son los estudios realizados en esta dirección, posiblemente el de CRUZ, J., "Las élites iberoamericanas a finales del siglo XVII", en HISMO, 1985, LADD, D. The Mexican Nobility at Independence, Austin University Press, Texas 1976 y sobre todo los trabajos de GUERRA, F.X., México: del Antiguo régimen a la Revolución, México, FCE, 1991, vol I y II y Modernidad e Independencias, Madrid, Mapfre, 1992, en donde teoriza más sobre el papel del absolutismo monárquico francés y sobre la monarquía española.

16. Este punto nos parece clave para entender la perdurabilidad de las redes en países con una tipología como la que hemos expuesto. La fortaleza de las redes radica en que operan en la sociedad civil como grupos de interés o de presión, son las que dominan la esfera del mercado, o de la producción, y solo en épocas de crisis o vacío de poder copan el Estado para recomponer el bloque dominante. Su capacidad de mimetismo y de metamorfosis, de emerger de la sociedad civil y retornar a ella en cualquier momento es el elemento que les confiere tanta fortaleza y permeabilidad.

17. Véase F.X. GUERRA, Modernidad e Independencias, BURKHOLDER, $M$. CHANDLER D.S., From Impotence to authotrity, The Spanish Crown and the American Audiencias 1687- 1808, University of Missouri Press, 1977. Asi como los trabajos de SELLERS, L., y CARLOS M. " Family Kinship structure and modernization in Latin America", en LARR, 1985 p. 95-125. Es de notable interés el análisis del papel de los "pactos interelitarios en su contexto.

18. Sobre el tema de las distintas legitimidades y tipos de dominio, existen poco estudios empíricos al respecto, sugerimos un retomo a los planteamientos weberianos sobre la legitimidad de los diferentes actores sociales y a los conceptos habermasianos sobre la crisis de legitimidad. Véase SERRANO GOMEZ, E. Legitimación y racionalización, Antrophos , México, 1994. ESCALANTE GONZALBO, F., Ciudedanos Imaginarios, México, Colegio de México, 1992.

A nuestro juicio la problemática del poder en América Latina y las crisis de gobermabilidad radican en la convivencia de diferentes tipo de de dominio y formas de legitimidad que se yuxtaponen y entran en conflictos permanentes desde la Colonia hasta nuestros dias. Véase CASAUS ARZU M. " El poder y la legitimidad en América Central" (en prensa).

19. Véase HALPERIN DONGHI J., Reoolución y guerra formación de una elite dirigente en la argentina criolla, México, Siglo XXI, 1979. LACOSTE P. A.," La lucha de élites en la Argentina: La Unión cívica radical en Mendoza 1890-1905", en Anuario de Estudios Americenos, CSIC, Sevilla 1993 tomo L, $\mathbf{n}^{\mathbf{2}}$ 1, p: 181-211. COSTA PINTO, L., Lutas de familias no Brasil, en MEC, Sao Paulo, 1980. BALMORI,D., VOSS, S. y WORTMAN, M., Las alianzas de familias y la formación...

20. La consolidación del Estado oligárquico se produjo de distinta manera en México, Argentina, Chile, Brasil o Centroamérica, pero en todos ellos dicho Estado liberal representó únicamente los intereses de las oligarquías, quienes aparentemente se sometieron a las reglas del juego de un Estado de derecho, pero continuaron ejerciendo un tipo de dominación clientelar, patriarcal y carismático, creando una imagen de Estado nacional que solo respondía a sus intereses. Véase CARMAGNANI, M., Estado y Sociedod 1850-1930, Barce- 
lona, Crítica 1984. HALPERIN DONGHI, T., Reforma y disolución de los imperios ibericos, 1750-1850, Madrid, Alianza América, 1985. ACUÑA V. H. (ed), Les Repuiblicas agroexportadoras, en Historia General de Centroamérica, vol IV, Flacso, V Centenario, Madrid, 1993.

21. Véase en GRAMSCI, A., el concepto de intelectual orgánico, en Introducción a la filosofia de la praxis, Barcelona, Península 1976 y en Antologia, México, Siglo XXI, 1986, asi como el libro de PORTELLI, H., El bloque histórico en Gramsci, México, Siglo XXI, 1980. Sobre la aplicación de este concepto a América Central, véase CASAUS ARZU M., Guatemala Linaje y Racismo, y SHELDON B. LISS, Radical Thought in Central America, Oxford Westview Press, 1991.

22. La familia Aycinena ha sido estudiada por BALMORI, D, VOSS, S y WORTMAN, M, Les alinnzas de familia..., op cit, 1990 y CASAUS ARZU, M, Guatemala: Linaje...op. cit.,1992. LEVI, D. A familia Prado, op cit..1977. BAHAMONDE A y CAYUELA J, Hacer las Américas, las élites coloniales españolas en el siglo XIX,, Madrid, Alianza América, 1992. DE LA PEN̄A, F. Oligarquía y propiedad en la Nueva España, 1550-1624, México, FCE, 1983.

23. El origen de la familia Meza Ayau, se encuentra en el siglo XIX, que se establece en Guatemala pasando después a El Salvador y funda la primera industria cervecera. Posteriormente la familia extendió sus negocios a la agricultura y agroindustria y en la actualidad se vincula al proceso de globalización a través del comercio y las finanzas. Un miembro de la red familiar Roberto Murray Meza, representa al grupo de la élite más modernizante e innovadora del país, fundando FUSADES y contribuyendo notablemente al proceso de pacificación y modernización de El Salvador. Colaboró estrechamente como asesor del gobiemo de Cristiani y continúa su labor con Calderón Sol.

24. El método prosopográfico nos permite estudiar la historia colectiva de una élite de poder, su vida, sus relaciones interpersonales, asi como sus comportamientos sociales y políticos. Para mayor información sobre este tema véase, STONE, L., El pasado y el presente, México, Siglo XXI, 1986. Así como STONE, L. Familia sexo y matrimonio en Inglaterra 1500-1800, México, FCE, 1989. En relación al concepto de Modernidad en la historia, véase los trabajos de F.X GUERRA, Modernidad e Independencias, Madrid, Mapfre, 1992. La Modernidad surge vinculada al período de la ilustración en el marco de la configuración del Estado Nación. Se trata de un conjunto de mutaciones en el campo de las ideas, de la cultura y del imaginario político, con el que los individuos y especialmente las élites, abordan el nuevo proyecto de Estado y de sociedad.

25. La información sobre esta familia esta tomada de GUIROLA LEAL,M, "Le familia Durán" en Reoista de la Academia de Estudios genealógicos Heráldicos e Históricos, en Guatemala, 1973, Pp: 199-334. GUIROLA LEAL, M, op. cit., p. 244.

26. El último matrimonio de la red de los Díaz Durán, el hijo de Fernando Andrade Díaz Durán, emparenta con la rama más poderosa de los Castillo, Castillo Love, dándose de nuevo en 1992 la unión de capital agrario,industrial y financiero y de dos de las familias más influyentes en la política y los negocios de la oligarquía guatemateca. Con ello queremos poner de mani- 
fiesto el reciclaje de las redes familiares en el siglo $X X$.

27. PELUPESSY, basándose en datos estadísticos elaborados para El Salvador y los investigados por nosotros en Guatemala, sobre la propiedad, el beneficio y las ganancias de los capitales más importantes del país, se llega a la conclusión de que la oligarquía ha mantenido su hegemonía en la fase agroindustrial durante las década de 1970 y 1980. Para Pelupessy, op. cit., el peso individual de cada familia de las 19 más importantes en El Salvador, no ha variado sustancialmente," no se han producido cambios drésticos en las relaciones de propiedad ni en los beneficios". Lo mismo ocurre en Guatemala, en donde la propiedad no fue afectada y los beneficios, en la etapa de crisis bélica no se vieron sustancialmente alterados.

28. Coincidimos con las afirmaciones de PELUPESSY y CORDOVA de que en El Salvador, la oligarquía que diversificó su producción en 1960 con el MCCA, y se tecnificó en los años 80 , no vió sustancialmente afectada su producción, ni sus ganancias, al contrario, en palabras de Pelupessy, "Con la base productida tecnificada y no mermada extraordinariamente por la guerra, la oligarquia no ha manifestado muchos sintomas de decadencia económica". A nuestro juicio, para el caso de Guatemala, viéndolo retrospectivamente, ciertos sectores, los más modernizantes, han salido claramente beneficiados y su poder económico y político fortalecido.

29. SARTI, C. op. cit y TAPIA G. " Los procesos electorales y su impacto", en Polémica, nu.11, 1990.p 61-68. MARSKI, M., Los empresarios y la transición en Guatemala, (mimeo), 1990, asi como CASAUS ARZU, M. " El rol de los empresarios modemizantes en el proceso de transición democrática en Guatemala, 1983-1994, ponencia presentada al IV Encuentro de Latinoamericanistas españoles, Salamanca, abril 1994.

30. Véase los programas del PAN, ARENA, PN y UNO y obsérvese las enormes similitudes existentes en materia económica, de modernización del Estado, en materia de derechos humanos, seguridad ciudadana y política energética y medio ambiente. No existe casi mención a los problemas sociales y escasa referencia a la necesidad de reformas sociales o derechos a las minorías étnicas. El programa del PAN ni siquiera menciona la existencia de indigenas en Guatemala.

31. Adolfo Boppel Carneta pertenecen a las redes oligarquicas entroncadas con los extranjeros y es dueño de dos grandes fincas en Suchitepequez: Zapotitlán y Pueblo Nuevo, ambas de café. Fue presidente de Anacafé en 1984 y presidente de Unagro en 1988 y miembro prominenete de CACIF. Posteriormente evoluciona hacia el sector de los no tradicionales. Está casado con otro miembro de la oligarquia Patricia Castañeda Padilla.

Los Alejos Arzú también poseen grandes extensiones de café como San Jacinto y Santa Rosa. Otro miembro del gabinete, y suegro de Serrano Elías, Arturo Bianchi posee la finca de San Lorenzo. Rodolfo Widman Luna, el suegro de Oscar Berger es uno de los más grandes cafetaleros del pais de origen alemán y posee en la actualidad las fincas de la Bolsa y anexo y los Jazmines y los Viteri tambien son dueños de la finca de Xelajú.

Otros miembros del gabinete como los Beltranena, Alejos Benfeldt, Arzú, Asturias, Berger Dorion, Castillo Sinibaldi, tambiên poseen fuertes intereses en la 
agroexportación de productos tradicionales como el café, azucar y ganado. Como podemos observar en el gabinete de la presidencia existe una fuerte presencia de miembros de la oligarquía tradicional dedicados al cultivo y a la, exportación del café. Resulta difícil considerar que sea una clase social en vias de evolución o pérdida de su capacidad económica y política.

32. Para más información sobre el tema véase CASAUS ARZU, M. "La metamorfosis de las oligarquias centroamericanas" en Centroamérica: Balance de la Década de los 80, Madrid, CEDEAL, 1993. Asi como La estructura social de Centroamérica, Madrid, AKAL, 1992 y "la recomposición del bloque en el poder y el retorno de las élites familiares centroamericanas (1979-1990), en BERCEO, Logroño, 124, 1993 P: 179-195.

Digitalizado por Biblioteca "P. Florentino Idoate, S.J." 
FAMIIIA BARAHONA CERRATU c Dxocrimetra git clatmira. saypor kinimas y costa inch

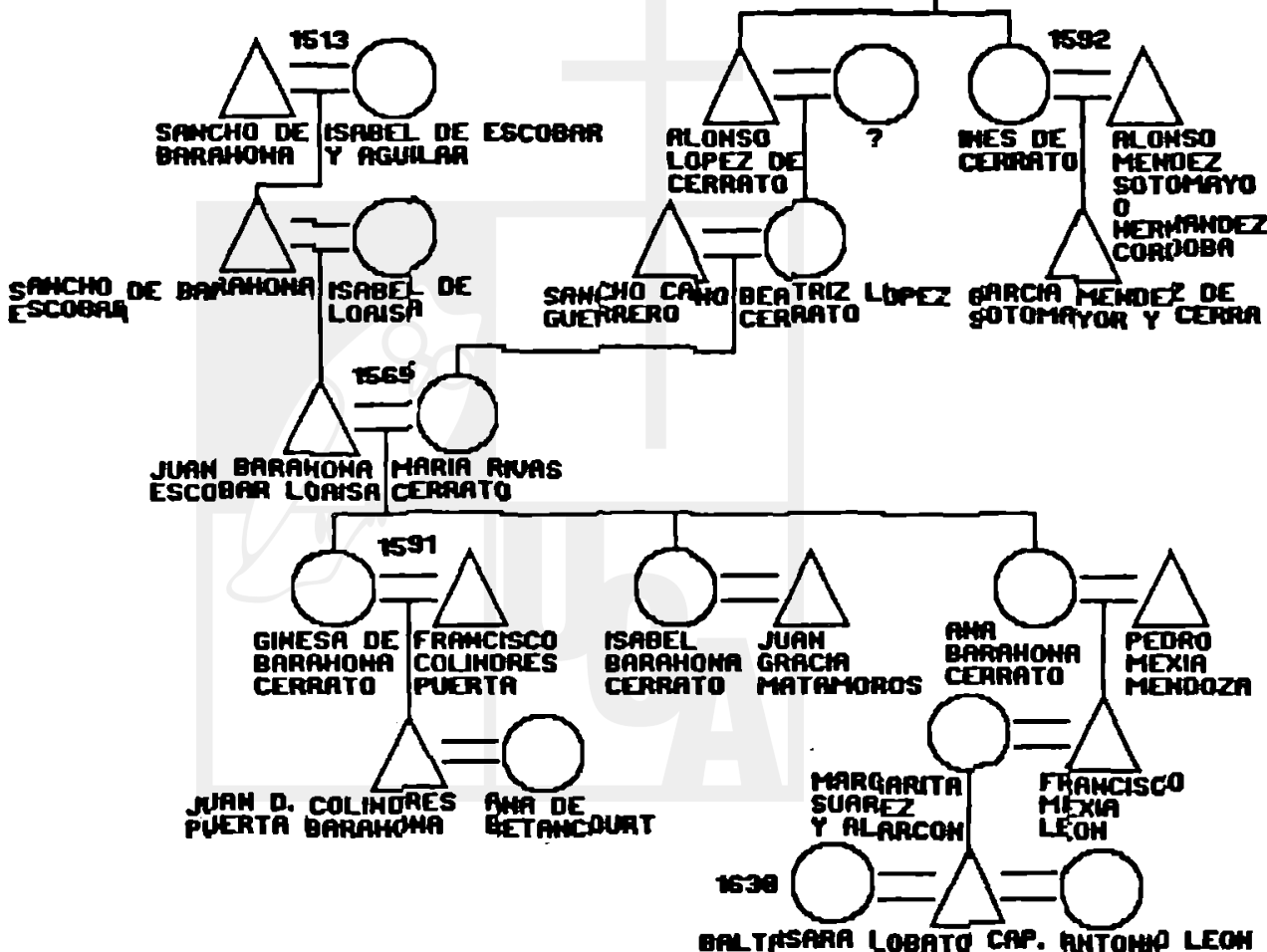

Digitalizado por Biblioteca "P. Florentino Idoate, S.J."

Universidad Centroamericana José Simeón Cañas 


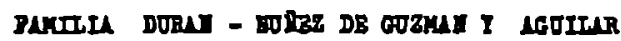

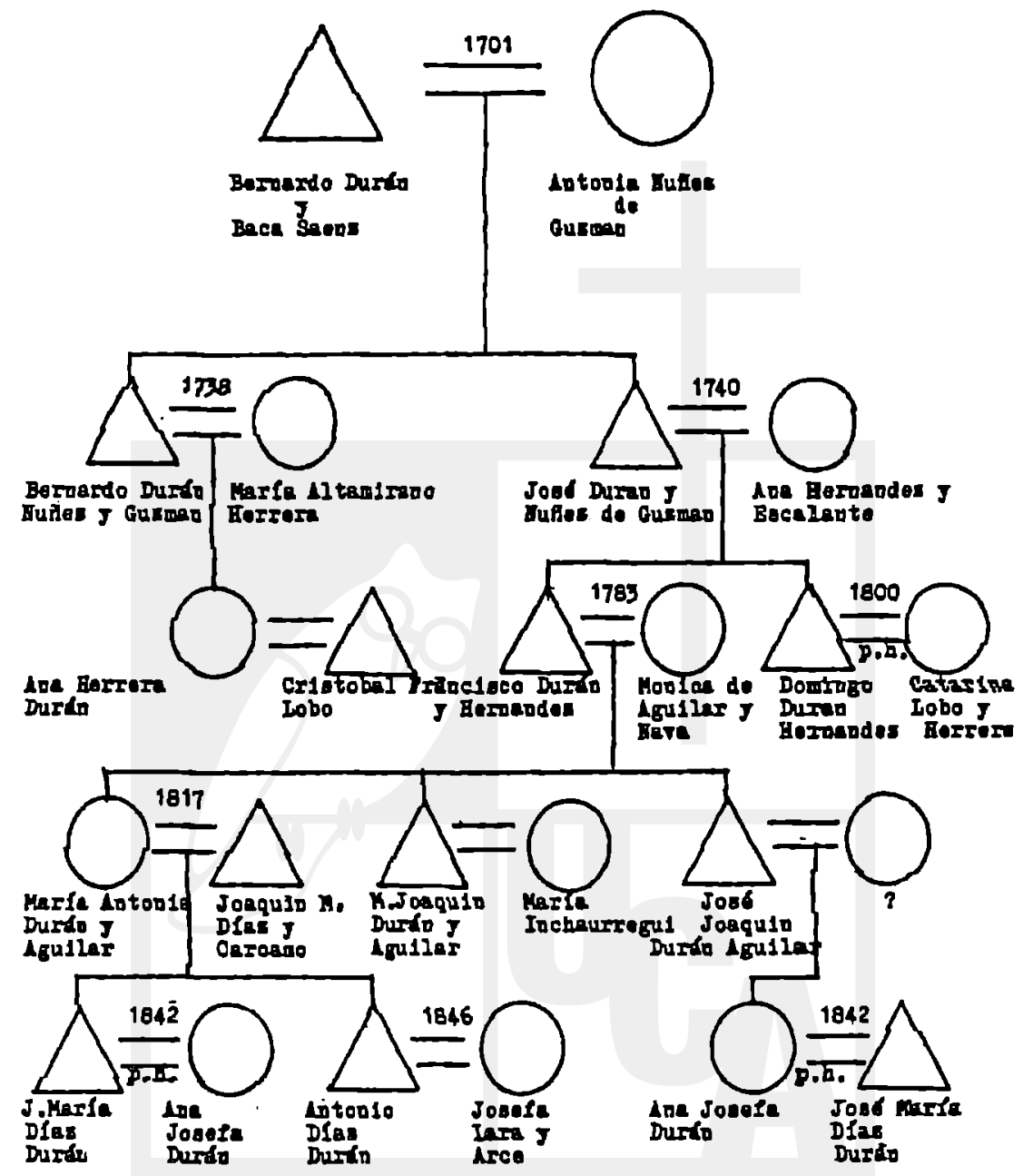

Digitalizado por Biblioteca "P. Florentino Idoate, S.J." Universidad Centroamericana José Simeón Cañas 


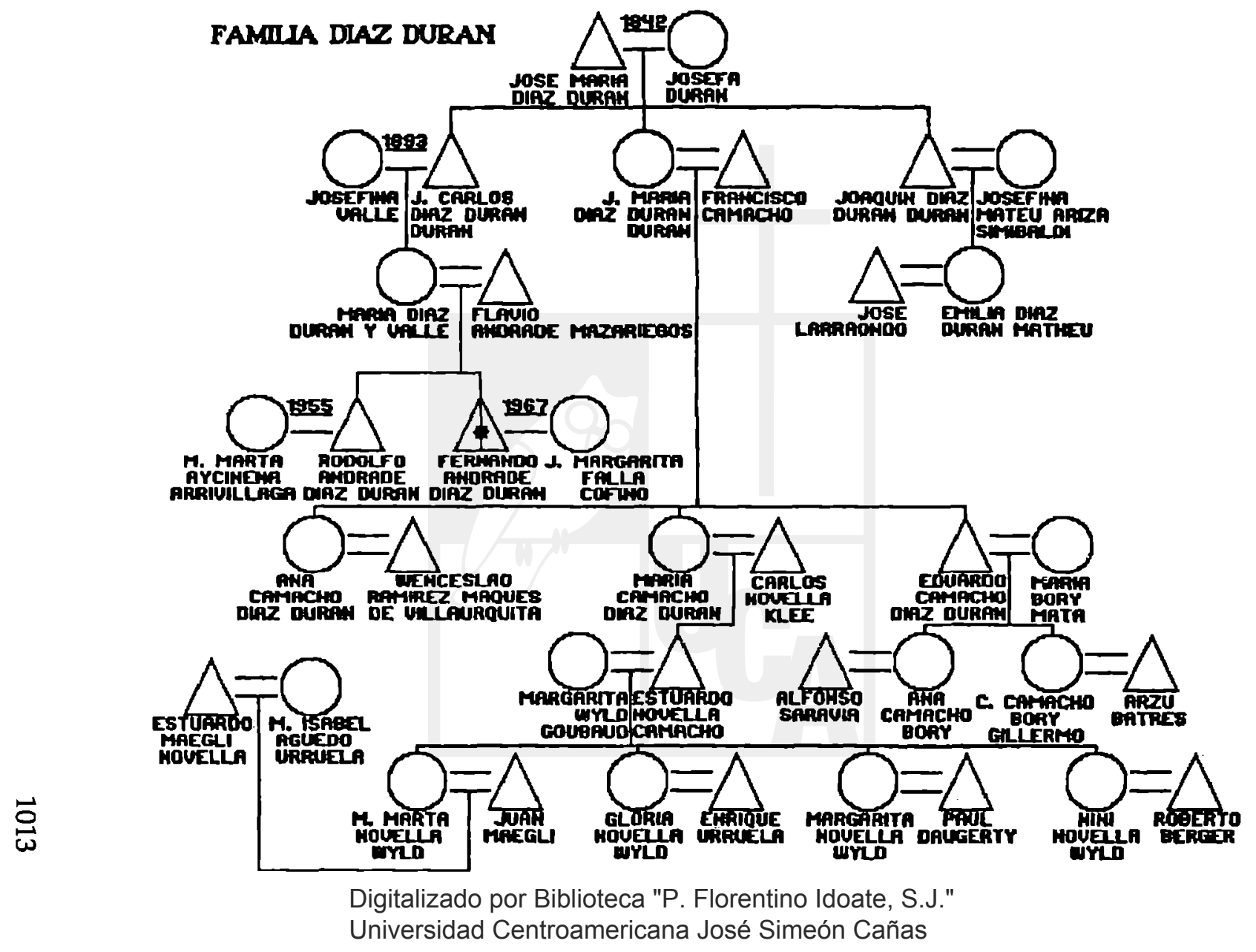




\section{EAMTLE OERE DURAN IRUMGARAY}
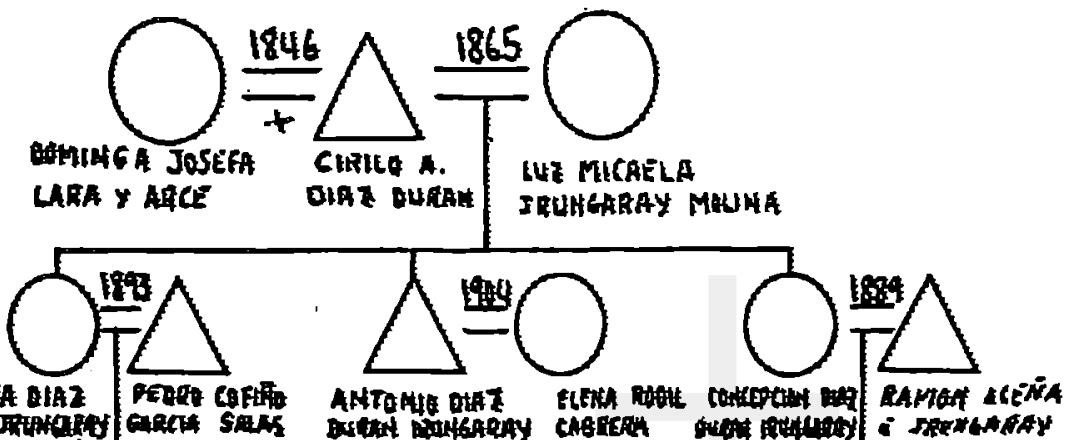

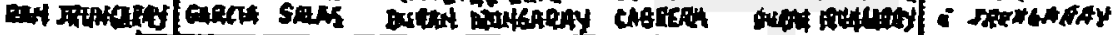

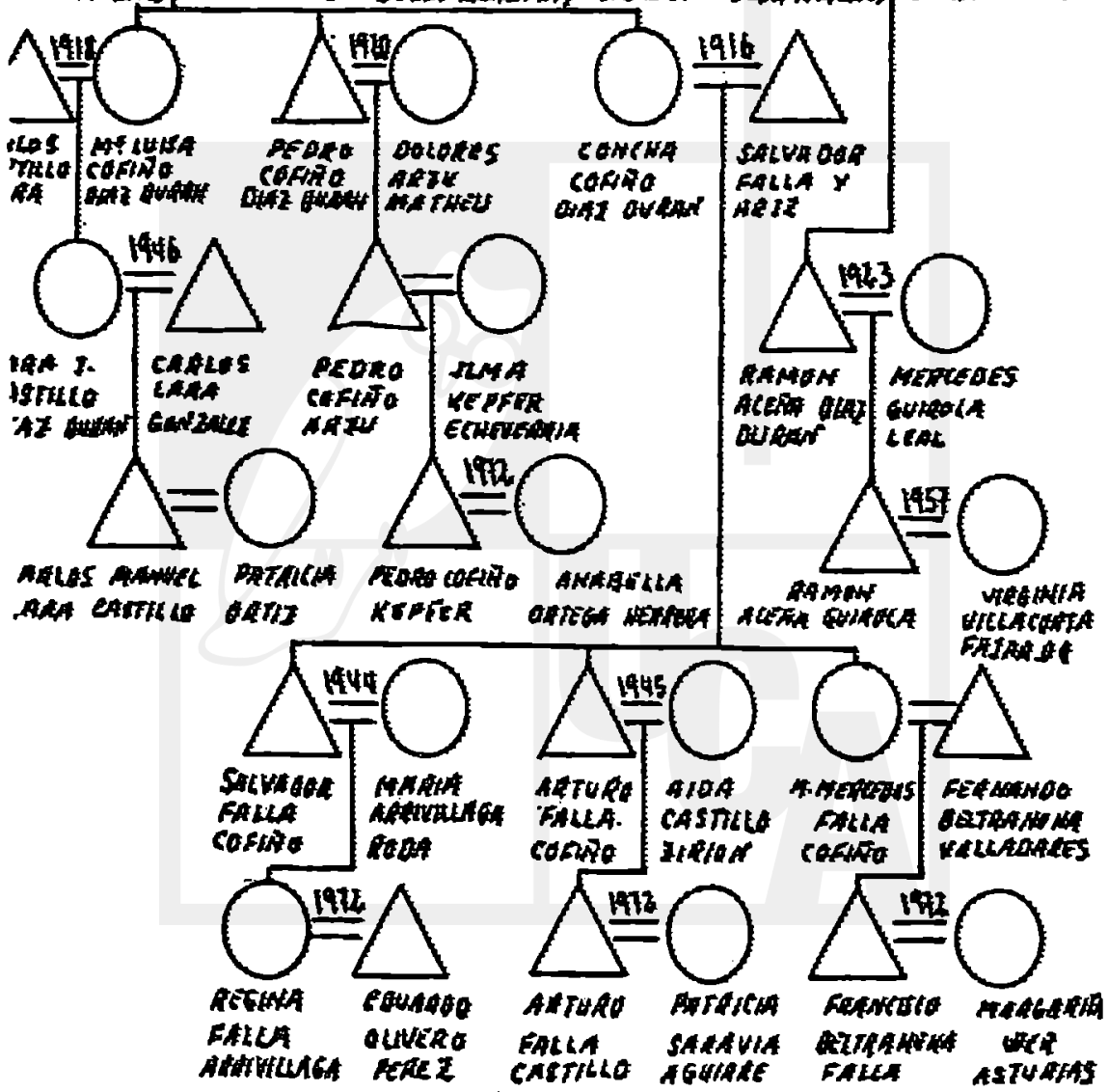

1014 